\title{
Research on Provincial Energy Rebound Effect in China
}

\author{
HAN Ying ${ }^{a}$, ZHAI Jie-lit SHI Jian-hua ${ }^{c}$ \\ Institute of Business Administration Northeastern University, Shenyang 110006, China \\ ahanying139@163.com, b1421102051@qq.com, '867204569@qq.com
}

\begin{abstract}
Key words: stochastic frontier; rebound effect; panel data; technical progress; influence factor Abstract: In view of the negligence of unbalanced development between regions in current research on the energy rebound effect in China, we provide a calculation method based on stochastic frontier production function. By using China's provincial panel data from 1977 to 2014, this paper estimates energy rebound effects. It concludes that: technical efficiency has significant difference, and rebound effects are quite different. If the rebound effect value is more than $100 \%$, tax and other means are needed to achieve energy saving goals.
\end{abstract}

\section{Introduction}

Since the rebound effect largely determines the realization of energy saving effect, it is particularly important to test whether there exists the rebound effect in China and estimate the rebound effect. Khazzoom ${ }^{[1]}$ initially estimated the rebound effect of household demand for heat supply from a microscopic perspective, he found that whether for electrically-heated homes or gas-heated homes, approximately two thirds of the initial saving due to the increased efficiency get eroded. Brookes ${ }^{[2]}$ reminded researchers that it is necessary to distinguish between engineering efficiency and economic efficiency. Then, the study of Khazzoom and Brookes is called as "Khazzoom-Brookes Postulate" by researchers. Saunders ${ }^{[3]}$ pointed out that the rebound effect is caused not only by the reduction of real energy price resulting from efficiency improvement but also by the promotion of economic growth to increase energy consumption.

But, the key hypothesis of the study above is that all producers can achieve the optimal production efficiency. This ideal hypothesis does not correspond to the reality. All regions achieving the input - output technical boundary is impossible. The stochastic frontier approach proposed by Aigner $^{[4]}$ can overcome this shortcoming. Considering the different regional technical efficiency. We establish a stochastic frontier production function model, which is more reliable for estimating the elasticity of capital, labor and energy and the calculating energy rebound effect.

\section{Theoretical model setting of the rebound effect}

Referring to Berkhout ${ }^{[5]}$, the rebound effect is defined as the ratio of energy consumption rebound to theoretical savings. And we calculate the additional energy demand and theoretical savings under the theory of neoclassical economic growth. Considering the vast territory of China and the unbalanced development between the provinces, we consider the impact of technical efficiency in estimating the contribution of technological progress to economic growth.

Based on the stochastic frontier research by Battese and Coelli ${ }^{[6]}$, we use the Cobb-Douglas stochastic frontier production function:

$$
Y_{i t}=A(t) K_{i t}^{\alpha} L_{i t}^{\beta} F_{i t}^{\gamma} \exp \left(\mathrm{v}_{i t} \cdot \mathrm{u}_{i t}\right)
$$

Where $Y_{i t}$ is the gross output, $K_{i t}$ is capital stock, $L_{i t}$ is labor, $F_{i t}$ is energy input; $\alpha, \beta$ 
and $\gamma$ are the output elasticity with respect to capital, labor and energy, $A(t)$ is the frontier technical efficiency level, $u_{i t}$ is production inefficiency, $v_{i t}$ is other random factors.

Taking logarithms on both sides of Eqs.(1) to Linearize the exponential production function:

$\ln Y_{i t}=\ln A(t)+\alpha \ln K_{i t}+\beta \ln L_{i t}+\gamma \ln F_{i t}-u_{i t}+v_{i t}$

According to Solow's, the contribution rate of technological progress can be expressed as:

$\sigma_{i, t+1}=1-\alpha \frac{g K_{i t}}{g Y_{i t}}-\beta \frac{g L_{i t}}{g Y_{i t}}-\gamma \frac{g F_{i t}}{g Y_{i t}}$

Where $\mathrm{g} Y_{i t}, g K_{i t}, g L_{i t}$ and $g F_{i t}$ represent growth rate of output, capital, labor and energy.

We define $\mathrm{g} Y_{i t}=\left(Y_{i, t+1}-Y_{i t}\right) / Y_{i t}$, and $g K_{i t} 、 g L_{i t}$ and $\mathrm{g} Y_{i t}$ are the same.

Then we define $E I_{i t}$ as energy intensity - the energy consumption per unit of output, thus $E I_{i t}=F_{i t} / Y_{i t}$, therefore, technological progress leads to higher energy efficiency (lower energy intensity), and the theoretical energy savings can be defined as:

$$
M_{i, t+1}=\left(E I_{i t}-E I_{i, t+1}\right) Y_{i, t+1}
$$

Also, Technological progress can contribute to the expansion of output scale, thus resulting in additional energy demand, and the new energy demand is:

$$
N_{i, t+1}=\sigma_{i, t+1}\left(Y_{i, t+1}-Y_{i, t}\right) E I_{i, t+1}
$$

According to the definition of rebound effect, the rebound effect caused by the technical progress can be define as:

$$
R_{i, t+1}=\frac{\sigma_{i, t+1}\left(Y_{i, t+1}-Y_{i, t}\right) E I_{i, t+1}}{\left(E I_{i t}-E I_{i, t+1}\right) Y_{i, t+1}}
$$

In Eq.(6), each variable can be calculated by applying statistical indicators except the contribution ratio of technical progress $\sigma_{i, t+1}$, and $\sigma_{i, t+1}$ need to be estimated by (2) and(3). When estimating $\sigma_{i, t+1}$, researches used to directly calculate it by C-D production function without considering the production inefficiency, but the production inefficiency is a very common phenomenon. More and more researches come to confirm that taking no account of $u_{i t}$ does not conform to the fact.

To estimate Eq. (2), we need to make clear the distributional hypothesis of $u_{i t}$ and $v_{i t} \cdot v_{i t}$ are traditional random variables, which are assumed to be iid. $N\left(0, \sigma_{v}\right) \cdot u_{i t}$ are non-negative random variables which are assumed to account for technical inefficiency in production and are assumed to be independently distributed as truncations at zero of the $N^{+}\left(m_{i t}, \sigma_{u}\right)$.

We define $I_{i t}$ as the proportion of exports to GDP ,and $O_{i t}$ as the proportion of oil consumption to the total energy consumption, then:

$$
m_{i t}=\delta_{0}+\delta_{1} I_{i t}+\delta_{2} O_{i t}
$$

The degree of opening-up is represented as the proportion of exports to GDP. Theoretically, the more foreign trade, the more access to new knowledge and advanced production technology. The quality of input factors is generally considered as the energy consumption structure, and this paper only considers the proportion of oil consumption to the total energy consumption in order to avoid multiple collinearity.

Combining Eq.(2) and(7), we can estimate the output elasticity of capital, labor, energy and the parameters of influencing factors, then calculate the contribution rate of technological progress by Eq.(3). Finally, we can calculate the energy rebound effect by Eq.(4) to (6). 


\section{Data sources}

The gross output is measured by regional GDP, and converted to 1997 constant prices. The stock of capital is measured by the capital stock. Referring to Shan's approach ${ }^{[7]}$, it can be estimated by Perpetual Inventory Method: $K_{t}=K_{t}-1(1-\eta)+I_{t}$, where $I_{t}$ are time series of fixed capital formation and are measured by price index of investment in fixed assets. $\eta$ is the depreciation rate, which are assumed as $10.96 \%$. Labor is measured by effective labor. Energy is measured by energy consumption (converted to standard coal). The degree of opening-up is represented as the proportion of exports to GDP. All forms of energy consumption are converted into standard coal. The oil includes crude oil, gasoline, kerosene, diesel fuel oil, natural gas, and the proportion of oil consumption is the ratio of oil consumption to total energy consumption. The above data are derived from the China Statistical Yearbook, the China Energy Statistical Yearbook, the Wind Database. A small number of missing data in some provinces were estimated by interpolation method. In this paper, the sample was collected from 30 provincial data from 1997 to 2014, with a total of 540 observation results(Tibet is not included).

\section{The calculation of provincial energy rebound effect in China}

To estimate Eq.(2)and (7), firstly, this study uses $\sigma^{2}=\sigma_{v}^{2}+\sigma_{u}^{2}$ and $\lambda=\sigma_{u}^{2} /\left(\sigma_{v}^{2}+\sigma_{u}^{2}\right)$ to replace $\sigma_{v}^{2}$ and $\sigma_{u}^{2}$, then estimate with three-step maximum likelihood estimation method: the first step is to estimate Eq.(2) by least square method to get unbiased estimation of $\alpha, \beta$ and $\gamma$; the second step is to use two-phase lattice search to get $\lambda$; the third step is to use the above values as initial values, and then obtain the maximum likelihood estimator by iteration. In this section, we select the software--frontier 4.1.

Table 1 shows the estimation results of the C-D stochastic frontier production function, we can see that unilateral likelihood ratio test of regression equation rejects the null hypothesis that technical efficiency does not exist, indicating that there exist development imbalances in different regions of China, and the technical efficiency of different regions has significant differences. In the same time, we can find that each parameter of the equation is very significant. In addition, the coefficient of the opening-up degree is negative, indicating that opening can promote the technical efficiency. The proportion of oil consumption is negative, indicating that upgrading the proportion of oil consumption can improve technical efficiency. Calculation results of rebound effect in representative years of eastern, central and western provinces are shown in table 2 to table 4 .

Table 1 The estimation results of Cobb Douglas stochastic frontier production function

\begin{tabular}{ccc|ccc}
\hline Coefficient & $\begin{array}{c}\text { Estimation } \\
\text { value }\end{array}$ & t-Statistic & Coefficient & $\begin{array}{c}\text { Estimation } \\
\text { value }\end{array}$ & t-Statistic \\
\hline$\alpha$ & $0.568^{*}$ & 43.54 & $\delta_{2}$ & $-0.453^{*}$ & -7.47 \\
$\beta$ & $0.421^{*}$ & 34.80 & $\sigma^{2}$ & $1.995^{*}$ & 13.69 \\
$\gamma$ & $0.115^{*}$ & 5.86 & $\lambda$ & $0.629^{*}$ & 6.89 \\
$\delta_{0}$ & $0.552^{*}$ & 20.00 & Log-L & \multicolumn{2}{|c}{323.56} \\
$\delta_{1}$ & $-0.639^{*}$ & -7.51 & LR & \multicolumn{2}{|c}{}
\end{tabular}


Table 2 The rebound effect values of representative years in eastern provinces (\%)

\begin{tabular}{c|c|c|c|c|c|c|c|c|c}
\hline Province & 1998 & 2000 & 2002 & 2004 & 2006 & 2008 & 2010 & 2012 & 2014 \\
\hline Beijing & 25.28 & 34.81 & - & - & 7.17 & 32.64 & 25.43 & - & 29.41 \\
\hline Tianjin & - & 19.82 & 36.62 & 176.81 & 16.4 & 15.47 & - & - & - \\
\hline Hebei & - & $*$ & $*$ & $*$ & 67.72 & - & 15.07 & - & - \\
\hline Liaoning & - & $*$ & 31.38 & $*$ & - & 1.27 & 19.48 & - & - \\
\hline Shanghai & 66.3 & 72.36 & 96.06 & 34.45 & 27.57 & 46.29 & 174.98 & 38.3 & - \\
\hline Jiangsu & 0.74 & - & 114 & $*$ & 67.33 & 53.11 & 18.04 & 23.36 & 46.12 \\
\hline Zhejiang & - & $*$ & $*$ & - & - & 23.73 & 53.32 & - & 49.48 \\
\hline Fujian & - & $*$ & $*$ & $*$ & - & - & 9.2 & 17.95 & - \\
\hline Shandong & - & $*$ & $*$ & $*$ & - & 16.01 & 8.67 & 10.77 & 22.9 \\
\hline Guangdong & - & - & 336.62 & $*$ & 80.78 & 14.46 & - & - & - \\
\hline Hainan & 6.37 & $*$ & $*$ & 33.55 & 434.41 & - & 20.96 & - & - \\
\hline
\end{tabular}

Note: - indicates no technical progress; * indicates no increase in energy efficiency.

Table 3 The rebound effect value of representative year in central provinces (\%)

\begin{tabular}{c|c|c|c|c|c|c|c|c|c}
\hline Province & 1998 & 2000 & 2002 & 2004 & 2006 & 2008 & 2010 & 2012 & 2014 \\
\hline Shanxi & - & - & $*$ & 40.69 & - & - & - & - & - \\
\hline Jilin & 4.56 & - & $*$ & - & - & - & - & 12.00 & - \\
\hline Heilongjiang & - & - & 29.88 & 338.16 & 45.73 & 20.95 & - & - & - \\
\hline Anhui & - & - & 42.98 & 110.23 & - & 1.34 & 18.63 & - & - \\
\hline Jiangxi & - & $*$ & $*$ & 52.18 & - & 26.92 & 54.76 & 27.79 & 135.61 \\
\hline Henan & - & - & $*$ & $*$ & - & - & - & - & - \\
\hline Hubei & - & - & $*$ & $*$ & - & 43.59 & 43.29 & 3.59 & 31.19 \\
\hline Hunan & - & - & $*$ & $*$ & - & 18.43 & 1.05 & 15.20 & 6.85 \\
\hline
\end{tabular}

Note: the same of table 2 .

Table 4 The rebound effect value of representative year in western provinces $\quad(\%)$

\begin{tabular}{c|c|c|c|c|c|c|c|c|c}
\hline Province & 1998 & 2000 & 2002 & 2004 & 2006 & 2008 & 2010 & 2012 & 2014 \\
\hline Inner Mongolia & - & - & - & $*$ & - & 12.42 & - & - & - \\
\hline Guangxi & - & $*$ & $*$ & $*$ & - & - & - & 30.86 & 4.25 \\
\hline Chongqing & $*$ & 0.65 & 9.11 & $*$ & - & 65.41 & 55.64 & 44.44 & 22.30 \\
\hline Sichuan & - & - & - & $*$ & - & 11.08 & 49.56 & 22.70 & 31.50 \\
\hline Guizhou & $*$ & - & - & 9.42 & 32.39 & 19.65 & 52.63 & 8.68 & - \\
\hline Yunnan & - & - & $*$ & $*$ & 14.81 & 36.92 & - & 98.49 & - \\
\hline Shanxi & - & - & - & $*$ & - & 24.43 & - & 7.73 & - \\
\hline Gansu & - & - & - & - & 60.86 & - & - & 43.24 & - \\
\hline Qinghai & - & - & - & $*$ & $*$ & 89.80 & 17.38 & - & - \\
\hline Ningxia & - & $*$ & $*$ & $*$ & - & - & - & 9.20 & - \\
\hline Xinjiang & - & 23.31 & - & $*$ & 68.67 & 55.54 & - & $*$ & - \\
\hline
\end{tabular}

Note: the same of table 2.

Table 2 4 shows that there exist different levels of rebound effect in the provinces, and the rebound effect at different times has no continuity, even in many cases there is no rebound effect. This is the major difference from the direct result of the Cobb-Douglas production function. The reason is the lack of technological progress. This suggests that the direct use of the Cobb-Douglas 
production function would overestimate the contribution of technological progress to the economy, and the frontier technology is not applicable to all provinces because of the different technical efficiencies in different regions. In fact, considering the spatial spillover effects of regional economies and the energy-economy nonlinear relationship. It also can conclude that there is no technical progress in some provinces in some years.

The eastern region frequently appears rebound and the rebound effect in the western region is relatively small showing that the rebound effect is likely to occur in developed areas, that is because the new technology is generally introduced from coastal open cities, and gradually spread to inland regions.

From the measurement results of the rebound effect, we can see that the majority of the rebound effect is less than $100 \%$, indicating that the increase in energy demand caused by the technological progress is less than energy savings due to improved energy efficiency. But in some provinces, where the rebound effect is more than $100 \%$, policies to save energy only by improving energy efficiency will fail, and the government will need to curb the rebound effect through a combination of tax and other means.

\section{Conclusion}

In view of the negligence of unbalanced development between regions in current research on the energy rebound effect, this paper provides a method to calculate the rebound effect based on the stochastic frontier production function. The empirical study of the rebound effect by using provincial panel data from 1997 to 2014 shows that: firstly, different regions do have different technical efficiencies, and assuming that all provinces have the same technical level is not appropriate. Secondly, there is no rebound effect in some provinces due to the absence of technological progress or improvement in energy efficiency. In addition, the rebound effect appeared more frequently in the eastern provinces, Finally, in recent years, the technical level of the western region has increased, especially in Sichuan and other places, and started to appear rebound effect frequently, warning that we need to pay attention to suppressing rebound effect while introducing the new technologies

\section{Acknowledgements}

This work was supported by the Liaoning Natural Science Foundation (201602267), a study on the mechanism and restraining mechanism of energy rebound in Liaoning equipment manufacturing industry.

\section{References}

[1] Khazzoom J D. Energy saving resulting from the adoption of more efficient appliances[J].The Energy Journal, 1987, 8(4): 85 89.

[2] Brookes L.Energy efficiency fallacies - a postscript[J].Energy Policy, 2004, 32(8): 945 947.

[3] Saunders H D.The khazzoom-brookes postulate and neoclassical growth[J].The Energy Journal, 1992, 13(4): 131 148.

[4] Aigner D, Lovell C K, Schmidt P. Formulation and estimation of stochastic frontier production function models[J].Journal of Econometrics, 1977, 6(1): 21 37.

[5] Berkhout P H, Muskens J C, Velthuijsen J W. Defining the rebound effect[J]. Energy Policy, 2000, 28(6): 425 432. 
[6] Battese G E, Coelli T J. A model for technical inefficiency effects in a stochastic frontier production function for panel data[J].Empirical Economics, 1995,20(2): 325 332.

[7] Shan Hao-jie. Reestimating the capital stock of china: 1952 2006[J]. The Journal of Quantitative \& Technical Economics, 2008, 25(10): 17-31. 